\title{
Facile synthesis of ferrocene-based polyamides and their organic analogues terpolyamides: Influence of aliphatic and aromatic sequences on physico- chemical characteristics
}

Tehmina Khan

zareen akhter

Asghari Gul

ARSHAD SALEEM Bhatti

Adeela Rehman ( $\square$ adeelarehman00@gmail.com )

Quaid-i-Azam University

\section{Research Article}

Keywords: Ferrocene based polyamides, terpolyamides, thermal behavior, limiting oxygen index, viscosity measurement

Posted Date: February 7th, 2022

DOI: https://doi.org/10.21203/rs.3.rs-1326062/v1

License: (c) (i) This work is licensed under a Creative Commons Attribution 4.0 International License. Read Full License

Version of Record: A version of this preprint was published at Journal of Inorganic and Organometallic Polymers and Materials on April 9th, 2022. See the published version at https://doi.org/10.1007/s10904022-02318-9. 


\section{Abstract}

Efforts have been devoted to synthesize and characterize processable polymers with desired properties. Herein, four different series of aromatic and aliphatic terpolyamides were prepared via solution phase polycondensation of 4,4'-oxydianiline and hexamethylenediamine (HMDA) with various diacids chlorides (isophthalyol dichloride, terepthalyol dichloride, 1, 1'- ferrocene dicarboxylic acid chloride and transazobenzene-4, 4'-dicarbonyl chloride). The structural, morphological and physico-chemical nature of as prepared polymers was explored by Fourier-transform infrared spectroscopy (FT-IR), scanning electron microscopy (SEM), thermal analysis (TGA and DSC), and wide-angle x-ray diffraction (WAXRD). Moreover, an aliphatic diamine was incorporated in varying concentration as a flexible methylene spacer and the effect of its concentration on the properties of polyamides was also studied. Changes in various physicochemical properties such as solubility, inherent viscosity, surface morphology and flame retarding behaviour were investigated. Marked difference in morphology and solubility was observed with the change in the ratio of segments in the chain. Inherent viscosities of polymers ranged from 1.8052-1.6274 $\mathrm{dl} / \mathrm{g}$ indicating reasonably moderate molecular weights. Interestingly, ferrocene based aromatic polymers were more thermally stable $\left(\mathrm{T}_{g} 260^{\circ} \mathrm{C}, \mathrm{T}_{\mathrm{i}} 310^{\circ} \mathrm{C}, \mathrm{T}_{\mathrm{h}} 525^{\circ} \mathrm{C}, \mathrm{T}_{\mathrm{f}} 720^{\circ} \mathrm{C}\right.$, for $\left.\mathrm{PF} \mathrm{F}_{0}\right)$, and also found to exhibit best flame retarding behavior (limiting oxygen index (LOI) value for $\mathrm{PF}_{0}$ is LOI $33.15 \%$ ).

\section{Introduction}

Polyamides continue to be one of the most promising class of polymers by virtue of their remarkable high temperature thermo-mechanical properties $[1,2]$. High temperature tolerance along with distinctive and versatile properties of polyamides has earned these thermoplastics a place among the high-performance engineering plastics. The characteristic features associated with each class of polyamides are conferred due to their variable structural aspects of the monomers. Aramids have rigid phenyl rings that impart stiffness to the polymer chain and dramatically increase the thermo-mechanical properties, abrasion resistance, chemical resistance, solvent resistance, and impart better properties like higher impact strength, low coefficient of thermal expansion comparable to the high-performance materials. However, the polymer processing via melt technique is difficult in aramids attributed to the formation of highly viscous melts. On contrary, Nylons, having aliphatic monomers, are silky materials that offer better chemical resistance, weathering properties, resilience and excellent abrasion resistance, though their thermo-mechanical properties are inferior to those of aramids. To circumvent the thermo-mechanical problems, incorporation of the metal ions into polymers has given a new dimension to the polymer science. This task has been eased by the synthesis of ferrocene-based polymers. This not only introduces the strong and stable iron as the metal center but also imparts firmness to the chains and characteristics associated to ferrocene such as flame retarding behavior, electroactivity, redox properties etc. $[3,4]$. Ferrocene has proved to enhance the features of the polymers to a great extent and has made them a profitable choice where materials are expected to show superior electroactivity, conductance and semiconductance, catalytic activity, optical properties, thermo-mechanical stability, magnetism and flameretarding behavior [5-7]. 
Recently, the properties of the polyamides are optimized by terpolymerization/copolymerization with other materials such as flexible spacers having their distinguishing features thereby incorporating the properties of both polyamides and the induced material with desirable features [8-10]. Consequently, the processibility of material is made easier without compromising over the loss of distinguishing features like stability and thermo-mechanical strength. Herein, the notion behind this effort was to investigate the effect of subsequent increase of a flexible spacer on certain physicochemical properties of polyamides. This task was achieved by introducing a six-membered methylene chain in various concentrations so as to observe the modifications generated in the properties and the ease in melt processing.

\section{Experimental}

\subsection{Materials}

Ferrocene $\left(m . p=173^{\circ} \mathrm{C}\right)$, triethylamine $\left(T E A, b . p=89^{\circ} \mathrm{C}\right)$, 4-nitrobenzoic acid (m.p=236 $\left.{ }^{\circ} \mathrm{C}\right)$, acetyl chloride (b. $\left.p=50^{\circ} \mathrm{C}\right), 4,4^{\prime}$-oxydianiline ( $\left.m . p=191^{\circ} \mathrm{C}\right)$ and aluminium chloride $\left(\mathrm{m} . \mathrm{p}=194{ }^{\circ} \mathrm{C}\right)$, were purchased from Fluka (Switzerland) and used as such whereas isophthaloyl chloride (IPC) (m.p=42 ${ }^{\circ} \mathrm{C}$ ) and terepthaloyl chloride (TPC) (m.p $=83^{\circ} \mathrm{C}$ ) were purchased from Aldrich (Germany). Potassium carbonate (anhydrous) (m. $\left.p=890^{\circ} \mathrm{C}\right)$, sodium hydroxide $\left(\mathrm{m} . \mathrm{p}=392^{\circ} \mathrm{C}\right.$ ) and thionyl chloride were obtained from Merck (Germany). Commercially available sodium hypochlorite solution was used having $12-15 \%$ strength per liter. 1,6-hexanediamine $\left(60 \%\right.$ aqueous solution, b. $\left.p=204^{\circ} \mathrm{C}\right)$ was purchased from Acros Organics (New Jersey, USA). All solvents used were purchased from Merck (Germany) whereas tetrahydrofuran (THF) was purchased from Riedel de Haën and dimethylsulfoxide (DMSO) was obtained from Fluka (Switzerland). All the solvents were dried and distilled before usage.

\subsection{Synthesis of Monomers}

\subsubsection{Synthesis of 1, 1'-ferrocenedicarboxylic acid chloride (FcDC)}

Synthesis of 1,1'-ferrocenedicarboxylic acid chloride is carried out via three-step procedure which involves synthesis of 1, 1'-diacetyl ferrocene followed by conversion into 1,1'-ferrocene dicarboxylic acid and finally to 1,1'-ferrocene dicarboxylic acid chloride [11-13].

\subsubsection{Synthesis of trans-azobenzene-4, 4 '-dicarbonyl chloride (TADC)}

Synthesis of trans-azobenzene-4,4'-dicarbonyl chloride (TADC) involved two steps comprising preparation of trans-azobenzene-4,4'-dicarboxylic acid followed by the conversion into acid chloride by the procedure as shown in Scheme 1 [13].

\subsection{Synthesis of polymers}


All the organic and ferrocene-based polymers are synthesized by Scheme 2. The pre-weighed mixture of aromatic and aliphatic diamines with various compositions (net quantity $1.88 \mathrm{mmol}$ ) were dissolved in $20 \mathrm{~mL}$ of dried THF in a pre-baked, two-necked, $250 \mathrm{~mL}$ round bottom flask equipped with a magnetic stirrer and a condenser. The reaction mixture was stirred for 15 minutes and then $10 \mathrm{~mL}$ of triethylamine (TEA) was added to the flask at $0^{\circ} \mathrm{C}$ which was maintained by ice bath. After stirring for 20 minutes, dicarbonyl chloride (1.92 $\mathrm{mmol}$ ) solution (in dried THF) was added drop wise to the flask with vigorous stirring. Temperature of the reaction mixture was raised slowly to the room temperature. After stirring for 5-6 hours, the reaction mixture was refluxed for 1 hour. The precipitated product was filtered, washed sequentially with THF and methanol to remove unreacted precursors and side products. The finally obtained polymer material was dried in vacuum for 24 hours.

\subsubsection{Synthesis of PF series}

\section{i. $P F_{0}$}

Aliphatic diamine 0\%, Aromatic diamine 100\% (1.88 mmol), Color: Brown. Yield: 84\%. FT-IR (in $\mathrm{cm}^{-1}$ ): 3333.9 (N-H), 3157 (Ar-H), 1637.2(C=O), $1601.4(\mathrm{~N}-\mathrm{H}), 1312.6$ (C-N), 1099.5 (C-O-C), 498.2 (Fe-Cp).

ii. $P F_{50}$

Aliphatic diamine 50\% (0.94 mmol), Aromatic 50\% (0.94 mmol), Color: Dark brown. Yield: 78\%. FT-IR (in $\mathrm{cm}^{-1}$ ): 3448.4-3284.9 (N-H), 3110-3082 (Ar-H), $2944.9\left(\mathrm{CH}_{2}\right), 1634.2(\mathrm{C}=\mathrm{O}), 1519.9(\mathrm{~N}-\mathrm{H}), 1273.3(\mathrm{C}-\mathrm{N})$, 1065.4 (C-O-C), 492.1 (Fe-Cp).

iii. $P F_{70}$

Aliphatic diamine 70\% (1.316 mmol), Aromatic 30\% (0.564 mmol), Color: Dark brown. Yield: $90 \%$. FT-IR (in $\mathrm{cm}^{-1}$ ): $3273.6(\mathrm{~N}-\mathrm{H}), 3167.8(\mathrm{Ar}-\mathrm{H}), 2930.1\left(\mathrm{CH}_{2}\right), 1622.3(\mathrm{C}=\mathrm{O}), 1531.6(\mathrm{~N}-\mathrm{H}), 1341.3(\mathrm{C}-\mathrm{N}), 1026.4(\mathrm{C}-\mathrm{O}-$ C), 475 (Fe-Cp).

iv. $P F_{90}$

Aliphatic diamine 90\% (1.692 mmol), Aromatic diamine 10\% (0.188 mmol), Color: Dark brown. Yield: 76\%. FT-IR (in cm ${ }^{-1}$ ): $3410.3(\mathrm{~N}-\mathrm{H}), 3135(\mathrm{Ar}-\mathrm{H}), 2920\left(\mathrm{CH}_{2}\right), 1652.6$ (C=0), $1535(\mathrm{~N}-\mathrm{H}), 1216(\mathrm{C}-\mathrm{N}), 511.7$ (Fe-Cp).

\subsubsection{Synthesis of PA Series}

$$
\text { i.PAO }
$$

Aliphatic diamine 0\%, Aromatic diamine 100\% (1.88 mmol), Color: Brown. Yield: 89\%. FT-IR (in cm $\mathrm{cm}^{-1}$ ): 3370.7 (N-H), 3095 (Ar-H), 1641.4 (C=0), $1531.9(\mathrm{~N}-\mathrm{H}), 1216.7(\mathrm{C}-\mathrm{N}), 1035.3$ (C-O-C).

ii. $P A_{50}$ 
Aliphatic diamine 50\% (0.94 mmol), Aromatic 50\% (0.94 mmol), Color: dark brown. Yield: 88\%. FT-IR (in $\mathrm{cm}^{-1}$ ): $3270.5(\mathrm{~N}-\mathrm{H}), 3030(\mathrm{Ar}-\mathrm{H}), 2970\left(\mathrm{CH}_{2}\right), 1628.1(\mathrm{C}=\mathrm{O}), 1530.6(\mathrm{~N}-\mathrm{H}), 1210.7(\mathrm{C}-\mathrm{N}), 1057.4(\mathrm{C}-\mathrm{O}-\mathrm{C})$.

iii. $P A_{70}$

Aliphatic diamine 70\% (1.316 mmol), Aromatic 30\% (0.564 mmol), Color: Brown. Yield: 84\%. FT-IR (in $\left.\mathrm{cm}^{-1}\right)$ : 3432.8-3317.8 (N-H), 3130-3050 (Ar-H), $2977.9\left(\mathrm{CH}_{2}\right), 1628.3(\mathrm{C}=\mathrm{O}), 1540.6(\mathrm{~N}-\mathrm{H}), 1264.2(\mathrm{C}-\mathrm{N})$, $1034.9(\mathrm{C}-\mathrm{O}-\mathrm{C})$.

iv. $P A_{90}$

Aliphatic diamine 90\% (1.692 mmol), Aromatic diamine 10\% (0.188 mmol), Color: Dark brown. Yield: 92\%. FT-IR (in cm ${ }^{-1}$ ): $3399.3(\mathrm{~N}-\mathrm{H}), 3134.6(\mathrm{Ar}-\mathrm{H}), 2969.1\left(\mathrm{CH}_{2}\right), 1635.8(\mathrm{C}=0), 1536.7(\mathrm{~N}-\mathrm{H}), 1262.4(\mathrm{C}-\mathrm{N})$.

\subsubsection{Synthesis of PT series}

i. $P T_{0}$

Aliphatic diamine 0\%, Aromatic diamine 100\% (1.88 mmol), Color: White. Yield: 87\%. FT-IR (in cm $\left.\mathrm{cm}^{-1}\right)$ : $3275.3(\mathrm{~N}-\mathrm{H})$, 3115-3048 (Ar-H), 2925-2869 ( $\left.\mathrm{CH}_{2}\right), 1641.2(\mathrm{C}=\mathrm{O}), 1529(\mathrm{~N}-\mathrm{H}), 1318(\mathrm{C}-\mathrm{N}), 1098.9(\mathrm{C}-\mathrm{O}-\mathrm{C})$.

ii. $P T_{50}$

Aliphatic diamine 50\% (0.94 mmol), Aromatic 50\% (0.94 mmol), Color: White. Yield: 82\%. FT-IR (in cm $\left.{ }^{-1}\right)$ : $3299.4(\mathrm{~N}-\mathrm{H}), 3115-3052$ (Ar-H), 1641.3 (C=O), $1543.3(\mathrm{~N}-\mathrm{H}), 1217.4$ (C-N), 1100.9 (C-O-C).

iii. $P T_{70}$

Aliphatic diamine 70\% (1.316 mmol), Aromatic 30\% (0.564 mmol), Color: White. Yield: 87\%. FT-IR (in $\left.\mathrm{cm}^{-1}\right)$ : $3307(\mathrm{~N}-\mathrm{H}), 3115-3048(\mathrm{Ar}-\mathrm{H}), 2936-2860\left(\mathrm{CH}_{2}\right), 1622.1(\mathrm{C}=0), 1538.2(\mathrm{~N}-\mathrm{H}), 1224(\mathrm{C}-\mathrm{N}), 1091.9(\mathrm{C}-$ $0-C)$.

iv. $P T_{90}$

Aliphatic diamine 90\% (1.692 mmol), Aromatic diamine 10\% (0.188 mmol), Color: White. Yield 86\%. FT-IR (in $\mathrm{cm}^{-1}$ ): $3305.7(\mathrm{~N}-\mathrm{H}), 2969.8\left(\mathrm{CH}_{2}\right), 1640.9(\mathrm{C}=0), 1526.8(\mathrm{~N}-\mathrm{H}), 1217(\mathrm{C}-\mathrm{N})$.

\subsubsection{Synthesis of PI Series}

i. $P_{O} O$

Aliphatic diamine 0\%, Aromatic diamine 100\% (1.88 mmol), Color: White. Yield: $92 \%$. FT-IR (in cm $\left.\mathrm{cm}^{-1}\right): 3259$ (N-H), 3025 (Ar-H), 1647.7 (C=O), $1525.3(\mathrm{~N}-\mathrm{H}), 1237.9(\mathrm{C}-\mathrm{N}), 1063$ (C-O-C). 
ii. $P I 50$

Aliphatic diamine 50\% (0.94 mmol), Aromatic 50\% (0.94 mmol), Color: White. Yield: 81\%. FT-IR (in cm $\left.{ }^{-1}\right)$ : 3412.7-3276.3 (N-H), 3130-3052 (Ar-H), $2938.1\left(\mathrm{CH}_{2}\right), 1646.3(\mathrm{C}=\mathrm{O}), 1525.7(\mathrm{~N}-\mathrm{H}), 1238(\mathrm{C}-\mathrm{N}), 1102.7(\mathrm{C}-\mathrm{O}-$ C).

iii. $P l_{70}$

Aliphatic diamine 70\% (1.316 mmol), Aromatic 30\% (0.564 mmol), Color: White. Yield: 87\%. FT-IR (in $\left.\mathrm{cm}^{-1}\right)$ : $3269.3(\mathrm{~N}-\mathrm{H}), 3160(\mathrm{Ar}-\mathrm{H}), 2968-2838.1\left(\mathrm{CH}_{2}\right), 1646.8(\mathrm{C}=\mathrm{O}), 1540.6(\mathrm{~N}-\mathrm{H}), 1324.4(\mathrm{C}-\mathrm{N}), 1106.0(\mathrm{C}-$ $0-C)$.

iv. $P l_{90}$

Aliphatic diamine 90\% (1.692 mmol), Aromatic diamine 10\% (0.188 mmol), Color: White. Yield: 89\%. FT-IR (in cm ${ }^{-1}$ ): $3289.8(\mathrm{~N}-\mathrm{H}), 3080(\mathrm{Ar}-\mathrm{H}), 2943-2856.4\left(\mathrm{CH}_{2}\right), 1624.3(\mathrm{C}=0), 1539.0(\mathrm{~N}-\mathrm{H}), 1286.2(\mathrm{C}-\mathrm{N}), 1152.6$ (C-O-C).

\subsection{Characterization}

Melt-temp, Mitamura Riken Kogyo Inc, Tokyo, Japan, was employed to take the melting temperatures of synthesized monomers using open capillary tubes. The samples in solid state were subjected for analysis of functional groups by FT-IR instrument, Nicolet 6700, Thermo scientific company, USA using direct sample by ATR mode. Mettler Toledo Perkin Models DSC-823 was used to obtain the DSC curves of polymer samples at a heating rate of $10^{\circ} \mathrm{C} / \mathrm{min}$ in nitrogen atmosphere ranging the temperature from room temperature to $600^{\circ} \mathrm{C}$ and using sapphire as an internal standard. Thermogravimetric analysis of polymers was performed on a Perkin-Elmer instrument TGA7 thermobalance. Samples were heated at rate of $10^{\circ} \mathrm{C} / \mathrm{min}$ under nitrogen atmosphere from room temperature to $900^{\circ} \mathrm{C}$. Polymer samples were analyzed by WAXRD using Philips 3040/60 X Pert PRO Diffractometer provided with a Cu- $\mathrm{K}_{\mathrm{a}}$ radiation source. Surface morphology was analyzed by SEM using a JOEL JSM-6460 instrument. Samples were made conducting by applying gold-coated tapes and were mounted on an Al stub under vacuum to check the changes in surface morphology with change in composition of terpolymers. Viscometric measurements of polymers were done at room temperature in DMSO using U-tube Ubbelohde's viscometer with $20 \mathrm{~mL}$ capacity. The data thus collected was used to obtain relative viscosity $\left(\eta_{\text {rel }}\right)$, specific viscosity $\left(\eta_{\text {sp }}\right)$, reduced viscosity $\left(\eta_{\text {red }}\right)$ and inherent viscosity $\left(\eta_{\text {inh }}\right)$.

\section{Results And Discussion}

Low temperature solution polycondensation route was adopted for the polymerization of diamines and diacid chlorides under inert conditions in the solvent, $\operatorname{THF}[14,15]$. The reaction is exothermic, thus, initially; the temperature of the reaction mixture was maintained at $0^{\circ} \mathrm{C}$ using ice bath to avoid the side 
reaction of the highly reactive acyl groups. It is well understood that THF is a better choice of solvent when moderate molecular weight polymers are required to be synthesized.

\subsection{Structural elucidation of synthesized terpolyamides}

To elucidate the structural composition and functionalities of as-prepared polymers, FT-IR spectra were obtained. The representative spectra of each series are shown in Figure 1.

The FTIR spectra showed a prominent single characteristic band in the region $3440-3270 \mathrm{~cm}^{-1}$ which is indicative of secondary amide $-\mathrm{N}-\mathrm{H}[16-18]$ showing the successful condensation of monomers. The second most projecting peak observed was around $1655-1625 \mathrm{~cm}^{-1}$ attributed to the stretching frequency of carbonyl of amide group. The lowering of stretching frequency can be attributed to conjugation as it extends the dipolar character of conjugated carbon to $\beta$-carbon also, thereby increasing the single bond character of carbonyl group. Another characteristic, but rather weak band associated with bending vibration of $\mathrm{N}-\mathrm{H}$ bond was observed around $1560-1520 \mathrm{~cm}^{-1}[19-21]$. Moreover, the peak for ether linkage of 4,4'-ODA appeared in the region $1106-1014 \mathrm{~cm}^{-1}$ whereas this band was altogether absent in aliphatic polyamides. The aromatic and aliphatic moieties are easily distinguished owing to the presence of their characteristic peaks in the FTIR spectra. Besides, ferrocene based-terpolyamides were marked by the presence of a sharp peak in the fingerprint region around $511-475 \mathrm{~cm}^{-1}$ indicating Fe-Cp ring's stretching vibrations. The slightly higher absorption frequencies of carbonyl functional group in case of isophthaloyl based terpolyamides than terepthaloyl grades was due to the hydrogen bonding of polyamides. It is known that the phenomenon is more extensive in case of more ordered polymer microstructures, as was observed in the case of terepthaloyl-based polymers. The same trend was expected in case of azo-based polymers as the monomer (TADC) is also para-functionalized. However, no appreciable increase in frequency was observed which might be due to the highly conjugated system present in azo-based monomer; thus, the expected increase in vibration frequency due to $\mathrm{H}$-bonding was compensated due to conjugation in same functional group [22].

\subsection{Solubility Behavior}

Aromatic terpolyamides were found to be completely insoluble in common organic solvents like THF, DMF, DMAc and DMSO, however, they exhibit good solubility in $\mathrm{H}_{2} \mathrm{SO}_{4}$ (Table 1) [23]. Interestingly, a subsequent increase in the solubility was observed with the increase in the aliphatic spacers in the polymer chain. In addition, upon treatment with trifluoroacetic acid (TFAA), the insoluble aromatic macro chains were found to be soluble in all the organic solvents attributed to the promising role of trifluoroacetic acid in overcoming the $\mathrm{H}$-bonding present among the chains. 
Table 1

Qualitative solubility data of synthesized terpolyamides.

\begin{tabular}{|c|c|c|c|c|c|c|}
\hline Sample Name & THF & DMF & DMSO & DMAC & $\mathrm{H}_{2} \mathrm{SO}_{4}$ & TFAA+ any organic solvent \\
\hline $\mathrm{PF}_{0}$ & - & -- & -- & - & ++ & ++ \\
\hline $\mathrm{PF}_{1}$ & -- & -- & +- & -- & ++ & ++ \\
\hline $\mathrm{PF}_{2}$ & -- & -- & +- & -- & ++ & ++ \\
\hline $\mathrm{PF}_{3}$ & -- & +- & ++ & +- & ++ & ++ \\
\hline $\mathrm{PF}_{4}$ & -- & +- & ++ & +- & ++ & ++ \\
\hline $\mathrm{PF}_{6}$ & +- & ++ & ++ & +- & ++ & ++ \\
\hline $\mathrm{PA}_{0}$ & -- & -- & -- & -- & ++ & ++ \\
\hline $\mathrm{PA}_{1}$ & -- & -- & -- & -- & ++ & ++ \\
\hline $\mathrm{PA}_{3}$ & -- & -- & -- & -- & ++ & ++ \\
\hline $\mathrm{PA}_{6}$ & -- & +- & ++ & ++ & ++ & ++ \\
\hline $\mathrm{PT}_{0}$ & -- & -- & -- & -- & ++ & ++ \\
\hline $\mathrm{PT}_{1}$ & -- & -- & -- & -- & ++ & ++ \\
\hline $\mathrm{PT}_{3}$ & -- & -- & -- & -- & ++ & ++ \\
\hline $\mathrm{PT}_{6}$ & -- & +- & ++ & ++ & ++ & ++ \\
\hline $\mathrm{PI}_{0}$ & -- & -- & +- & -- & ++ & ++ \\
\hline $\mathrm{Pl}_{1}$ & -- & +- & +- & +- & ++ & ++ \\
\hline $\mathrm{Pl}_{3}$ & -- & +- & ++ & +- & ++ & ++ \\
\hline $\mathrm{PI}_{6}$ & - - & ++ & ++ & ++ & ++ & ++ \\
\hline
\end{tabular}

\subsection{Thermal Analysis}

Thermal analysis (TGA\& DSC) was carried out at the heating rate of $10^{\circ} \mathrm{C} / \mathrm{min}$ in nitrogen atmosphere. The following parameters were determined to estimate the thermal stability of polymers were initial temperature $\left(T_{i}\right)$ at which weight loss started, temperature at $50 \%$ weight loss $\left(T_{h}\right)$, final temperature $\left(T_{f}\right)$ at which maximum weight loss occurred, char residue (CR) at the end of experiment at $\left(T_{f}\right)$ and the 
limiting oxygen index (LOI) values, as shown in Table 2. The stability of aliphatic repeating units was expected to be less as compared to the aromatic repeating units owing to the resonance stabilized aromatic moieties which required additional thermal energy to undergo degradation as compared to the aliphatic $\mathrm{C}-\mathrm{H}$ bond with the reduced dissociation energy.

Table 2

Thermal analysis data of synthesized terpolyamides.

\begin{tabular}{|c|c|c|c|c|c|c|}
\hline Polymer sample & $\begin{array}{l}\mathrm{T}_{\mathrm{g}} \\
\left({ }^{\circ} \mathrm{C}\right)\end{array}$ & $\begin{array}{l}\mathrm{T}_{\mathrm{i}} \\
\left({ }^{\circ} \mathrm{C}\right)\end{array}$ & $\begin{array}{l}\mathrm{T}_{\mathrm{h}} \\
\left({ }^{\circ} \mathrm{C}\right)\end{array}$ & $\begin{array}{l}T_{f} \\
\left({ }^{\circ} \mathrm{C}\right)\end{array}$ & Char Residue (\%) & $\begin{array}{l}\text { LOI } \\
\text { (\%) }\end{array}$ \\
\hline $\mathrm{PF}_{0}$ & 260 & 310 & 525 & 720 & 39.12 & 33.15 \\
\hline $\mathrm{PF}_{1}$ & 202 & 250 & 460 & 690 & 32.31 & 30.42 \\
\hline $\mathrm{PF}_{3}$ & 147 & 227 & 428 & 572 & 26.68 & 28.17 \\
\hline $\mathrm{PF}_{6}$ & 108 & 185 & 357 & 527 & 12.68 & 22.57 \\
\hline $\mathrm{PA}_{0}$ & 180 & 230 & 430 & 582 & 38.16 & 32.40 \\
\hline $\mathrm{PA}_{1}$ & 134 & 189 & 383 & 495 & 25.31 & 27.60 \\
\hline $\mathrm{PA}_{3}$ & 119 & 160 & 347 & 485 & 19.40 & 25.30 \\
\hline $\mathrm{PA}_{6}$ & 106 & 153 & 333 & 440 & 7.10 & 20.34 \\
\hline $\mathrm{PT}_{0}$ & 172 & 300 & 564 & 670 & 12.10 & 22.34 \\
\hline $\mathrm{PT}_{1}$ & 149 & 280 & 508 & 658 & 7.90 & 20.66 \\
\hline $\mathrm{PT}_{3}$ & 120 & 248 & 478 & 640 & 4.43 & 19.27 \\
\hline $\mathrm{PT}_{6}$ & 97 & 213 & 337 & 485 & 2.70 & 18.58 \\
\hline $\mathrm{PI}_{0}$ & 155 & 208 & 460 & 572 & 22.20 & 26.38 \\
\hline $\mathrm{Pl}_{1}$ & 116 & 198 & 428 & 527 & 5.80 & 19.82 \\
\hline $\mathrm{Pl}_{3}$ & 110 & 182 & 357 & 478 & 5.20 & 19.58 \\
\hline $\mathrm{PI}_{6}$ & 91 & 150 & 288 & 395 & 1.45 & 18.08 \\
\hline
\end{tabular}

From Table 2, the thermal data revealed that the excellent thermal stability of all four series was associated with ferrocene-based terpolyamides. This can be attributed to the presence of a metal atom in the polymer architecture which imparted additional strength to the polymer chains [24]. The terephthaloylbased terpolyamides also showed better thermal stability due to their highly ordered and consistently stacked polymer chains because of the para-catenation of the monomers. Additionally, glass transition 
temperatures were quite in agreement with values reported in literature [25]. The subsequent addition of flexible methylene spacer was expected to decrease the glass transition temperature, but the decrease was not observed in a regular fashion instead a general decreasing trend was seen as depicted by Figure 2. Char residue which was left at final degradation temperature was also indicative of thermal stability of polymer [26]. Noteworthy, char residues were found to be higher for ferrocene-based terpolymers.

Moving forward, flame retarding behavior of synthesized terpolyamides was estimated by determining the limiting oxygen index (LOI) values which can be estimated from the char residue. Greater the char residue, higher would be the LOI values and more would be the flame retarding behavior. It is known that the polymers having LOI values greater than 21 are flame retarding materials whereas the polymers having LOI values higher than 33 are known to be self-extinguishing polymers [27]. LOI values can be found by applying the Van Krevelen-Hoftyzer equation (eq. 1) [28].

$\mathrm{LOI}=17.5+0.4 \mathrm{CR} .(1)$

The flame retarding behaviors were found to be best in case of ferrocene-based terpolymers as compared to the rest of analogues, signifying the beneficial role of iron atom which is left in the char in form of iron oxide and is resistant to further degradation.

\subsection{WAXRD Analysis}

Surface morphology of terpolyamides (whether crystalline or amorphous) was determined by wide angle $X$-Ray diffraction. Diffraction patterns were obtained at room temperature in the region $2 \theta=15-30^{\circ}$, which is typical of polymers. From the diffractograms, Figure 3 , it is evident that the ferrocene-based terpolyamides were amorphous in nature whereas the other polymers showed crystalline morphology. Among the organic terpolyamides, terephthaloyl-based polymers exhibited more crystalline nature [29]. This depicted that the para-catenation of the monomers led to the closed and ordered packing of polymer chains.

The bulky ferrocene moieties caused disruption in polymer chains thereby preventing the ordered arrangement of polymer microstructure, thus, were amorphous in nature [30]. By increasing the aliphatic content, polymers showed progression from semi-crystalline to amorphous behaviors. This is because the chain packing was disorganized due to increase in flexible linkage which subsequently leads to decrease in stiff aromatic linkages in polymer chains [31]. A broad background, with few minor peaks, was observed in case of ferrocene-based terpolyamides revealing the amorphous nature [30]. All terpolyamides had crystalline structure and showed resistance towards common organic solvents which is in agreement with the general trend reported that increasing the crystallinity tends to decrease the solubility. Additionally, the amorphous nature of these DMSO soluble terpolyamides could be due to the presence of bulky ferrocene moiety that makes them incapable of getting a regular ordered structure.

\subsection{Viscometric analysis}


The viscosity data was obtained using polymer solutions in DMSO by U-tube Ubbelohd's viscometer at room temperature. The inherent viscosities of all polymers ranged from 1.8052-1.6274 dl/g showing that polymers solutions were quite viscous which is indicative of the fact that polymers formed have reasonable molecular weights [32-34].

From the data, it is revealed that the ferrocene-based polymers have highest ranges of viscosity and with increasing concentration of flexible methylene linkage, a decreasing trend in viscosity was observed for all synthesized polymers. The data plots (Figure 4) showed that with the decrease in the concentration of aromatic diamine, viscosity was decreased. This could be attributed to free volume created in between the polymer chains due to introduction of flexible methylene linkage, thereby decreasing the viscosity of polymers. The data further highlighted that the strong $\mathrm{H}$-bonding operative in polymer structural design sourced the unusually high viscous flow of polyamide solutions as compared to other classes of polymers.

\subsection{SEM Analysis}

From the surface morphological analysis of synthesized terpolyamides (Figure 5), it is evident that organic terpolyamides had surface features resembling that of sphere-shaped particles whereas ferrocene-based terpolyamides showed sponge like appearance [35-39]. The introduction of an aliphatic diamine along with an aromatic diamine showed marked effect on surface topology of polymers, which was clearly depicted in micrographs. Progression from low percentage of flexible spacer to higher percentage had rendered a marked effect by making surface more compact and undistinguished. Henceforth, by increasing the aliphatic content of terpolyamides, surfaces can be made smoother and lubricating. Also, porosity of polymer can be decreased, thereby making it fit for use in various fields where smooth, lubricating and compact surface coatings and materials are required. Conclusively, the diverse morphology of all grades showed that we have successfully altered composition of aliphatic diamine in terpolyamides [40].

\section{Conclusions}

In the present study, polymers containing aliphatic and aromatic spacers were synthesized and characterized successfully in order to investigate the effect of increase in concentration of methylene spacer (HMDA) and to explore the subsequent changes in various physico-chemical properties. The objective was achieved as remarkable improvement in the properties of the synthesized polymers pertaining to the solubility, crystallinity, thermal stability, viscosity, surface morphology and flame retarding behavior was observed. Summarizing, the present study opens new gateways for designing the high-performing materials by varying the ratio of sequences and processable materials which consequently leads to desired physico-chemical attributes and tailored thermal and surface properties to be used for smooth, lubricating, and compact surface coatings and various other potential applications.

\section{Declarations}


Acknowledgements

The authors would like to thank University Research Fund, Quaid-i-Azam University, Islamabad, for the financial support of this project.

\section{Author contribution}

Tehmina Khan: Conceptualization, Methodology, Experimentation, Data Acquisition, Writing original draft - Review \& Editing. Zareen Akhter. Writing, Review and Editing, Supervision, Funding acquisition. Asghari Gul: Review and Editing. Arshad. S. Bhatti: Review and Editing, Adeela Rehman: Writing, Review and Editing.

\section{References}

1. T.W. Lee, S. Lee, S.M. Park, D. Lee Mechanical, thermomechanical, and local anisotropy analyses of long basalt fiber reinforced polyamide 6 composites Compos. Struct., 222 (2019), p. 110917

2. Y. Gao, W. Zhang, D. Li, X. Lin, X. Qiao, H. Niu et al., Novel polyamides containing asymmetric diamine designed and synthesized towards electrochromic and resistance memory device Synth. Met. 274, 116732 (2021)

3. F. Dumur Recent advances on ferrocene-based photoinitiating systems Eur. Polym. J., 147 (2021), p. 110328

4. B.U. Amin, H. Yu, L. Wang, S. Fahad, A. Nazir, F. Haq et al. Synthesis and Anti-migration Studies of Ferrocene-Based Amides as Burning Rate Catalysts J. Inorg. Organomet. P, 31 (2021), pp. 2511-2520

5. Y. Yang, Z. Lai Ferrocene-based porous organic polymer for photodegradation of methylene blue and high iodine capture Microporous Mesoporous Mater., 316 (2021), p. 110929

6. T.L. Bennett, L.A. Wilkinson, J.M. Lok, R.C. O’Toole, N. J. Long Synthesis, Electrochemistry, and Optical Properties of Highly Conjugated Alkynyl-Ferrocenes and-Biferrocenes Organometallics, 40 (2021), pp. 1156-1162

7. R.K. Mishra, T. Eren, D. Y. Wang Inorganic Polymers as Flame-Retardant Materials. Smart Inorganic Polymers: Synthesis, Properties, and Emerging Applications in Materials and Life Sciences (John Wiley \& Sons, 2019), pp. 197-241

8. Z. Zhang, M.H. Litt, L. Zhu Achieving relaxor ferroelectric-like behavior in nylon random copolymers and terpolymers Macromolecules, 50 (2017), pp. 9360-9372

9. S. Yilmaz, O. Gul, T. Yilmaz Effect of chain extender and terpolymers on tensile and fracture properties of polyamide 6 . Polymer $65,63-71$ (2015)

10. A. Datta Sarma, H.R. Padmanathan, S. Saha, S. Shankar Banerjee, A. K. Bhowmick Design and properties of a series of high-temperature thermoplastic elastomeric blends from polyamides and functionalized rubbers J. Appl. Polym. Sci., 134 (2017), p. 45353 
11. M. Rosenblum, R. B. Woodward The structure and chemistry of ferrocene. III. Evidence pertaining to the ring rotational barrier J. Am. Chem. Soc., 80 (1958), pp. 5443-5449

12. F.W. Knobloch, W. H. Rauscher Condensation polymers of ferrocene derivatives J. Polym. Sci., 54 (1961), pp. 651-656

13. M.S.U. Khan, A. Nigar, M.A. Bashir, Z. Akhter A New Ferrocene-Containing Polyamide Prepared from an Improved Synthesis of 1, 1'-Ferrocene Dicarbonyl Chloride and Ferrocene-Based Diamine Synth. Commun., 37 (2007), pp. 473-482

14. J.A. Reglero Ruiz, M. Trigo-López, F.C. García, J. M García Functional aromatic polyamides Polymers 9, 414 (2017)

15. K.I. Aly, A.H. Moustafa, E.K. Ahmed, H.M. Abd El-lateef, M.G. Mohamed, S.M. Mohamed et al. New polymer syntheses part 60: a facile synthetic route to polyamides based on thieno [2, 3-b] thiophene and their corrosion inhibition behavior Chinese J. Polym. Sci., 36 (2018), pp. 835-847

16. B. Jović, M. Panić, N. Radnović, K. Živojević, M. Mladenović, V. Crnojević et al. Investigation of the surface interactions of selected amides with mesoporous silica using FTIR spectroscopy and hyperspectral imaging J. Mol. Struct., 1219 (2020), p. 128562

17. A. Rehman, S. J. Park Preparation and Characterization of Polyamides and Nitrogen-doped Carbons for Enhanced $\mathrm{CO}_{2}$ Capture Bull. Korean Chem. Soc. 38, 1285-1292 (2017)

18. M. Čolović, J. Vasiljević, Ž Štirn, N. Korošin, M. Šobak, B. Simončič et al. New sustainable flame retardant DOPO-NH-functionalized polyamide 6 and filament yarn Chem. Eng. J., 426 (2021), p. 130760

19. C. Zhou, S. Qi, P. Zhu, Y. Zhao, Y. Xu, X. Dong et al. The methylene infrared vibration and dielectric behavior monitored by amide group arrangement for long chain polyamides Polymer, 190(2020), p. 122231

20. M. Kaur, R. Kaur, K. S. Samra Luminescent behavior of semiconductor doped polyamide AIP Conf. Proc., 1860 (2017), p. 020004

21. A.S. Patil, M. Medhi, N.V. Sadavarte, P.P. Wadgaonkar, N. N. Maldar Synthesis and characterization of novel aromatic-aliphatic polyamides from bis-[(4-aminobenzyl)-4-benzamide] ether Mater. Sci. Eng. B, 168 (2010), pp. 111-116

22. Y. Liu, S. Jiang, W. Yan, J. Qin, M. He, S. Qin et al. Enhanced mechanical and thermal properties of polyamide 6/p (N-(4-F-phenylmaleimide) - alt-styrene) composites based on interfacial complexation inducing crystal transformation Polymer, 214 (2021), p. 123237

23. Z. Yu, R. Deng, G. Rao, Y. Lu, Y. Wei, C. Fu et al. Synthesis and characterization of highly soluble wholly aromatic polyamides containing both furanyl and phenyl units J. Polym. Sci., 58 (2020), pp. $2140-2150$

24. Y. Vidavsky, M.R. Buche, Z.M. Sparrow, X. Zhang, S.J. Yang, R.A. DiStasio Jr. et al., Tuning the mechanical properties of metallopolymers via ligand interactions: a combined experimental and theoretical study Macromolecules, 53 (2020), pp. 2021-2030 
25. R. Xie, A.R. Weisen, Y. Lee, M.A. Aplan, A.M. Fenton, A.E. Masucci et al. Glass transition temperature from the chemical structure of conjugated polymers Nat. Commun., 11 (2020), pp. 1-8

26. N. Mandlekar, A. Cayla, F. Rault, S. Giraud, F. Salaun, G. Malucelli et al. Thermal stability and fire retardant properties of polyamide 11 microcomposites containing different lignins Ind. Eng. Chem. Res., 56 (2017), pp. 13704-13714

27. E.M. Mansour, A.A. Iskander, H. H. Hassan Synthesis, thermal and optical properties of nanosized polyamides containing $\mathrm{N}$-phenyl-and $\mathrm{N}$-naphthyl-s-triazine rings: structure-properties correlation $\mathrm{J}$. Macromol. Sci. A, 54 (2017), pp. 105-117

28. D.W. Van Krevelen Some basic aspects of flame resistance of polymeric materials Polymer, 16 (1975), pp. 615-620

29. Z. Cheng, D. Liao, X. Hu, W. Li, C. Xie, H. Zhang et al., Synergistic fire retardant effect between expandable graphite and ferrocene-based non-phosphorus polymer on polypropylene Polym. Degrad. Stab. 178, 109201 (2020)

30. M.S.U. Khan, Z. Akhter, T. Naz, A.S. Bhatti, H.M. Siddiqi, M. Siddiq et al., Study on the preparation and properties of novel block copolymeric materials based on structurally modified organometallic as well as organic polyamides and polydimethylsiloxane Polym. Int. 62, 319-334 (2013)

31. A. Rehman, S. J. Park Facile synthesis of nitrogen-enriched microporous carbons derived from imine and benzimidazole-linked polymeric framework for efficient $\mathrm{CO}_{2}$ adsorption J. CO2 Util., 21 (2017), pp. 503-512

32. J. Rezania, M. Hayatipour, A. Shockravi, M. Ehsani, V. Vatanpour Synthesis and characterization of soluble aromatic polyamides containing double sulfide bond and thiazole ring Polym.76 (2019), pp. 1547-1556

33. J.M. Pérez-Francisco, W. Herrera-Kao, M.O. González-Díaz, M. Aguilar-Vega, J. L. Santiago-García Assessment of random aromatic co-polyamides containing two different bulky pendant groups. J. Appl. Polym. Sci. 135, 45884 (2018)

34. S. Russo, A. Mariani, V.N. Ignatov, I. I. Ponomarev High-molecular-weight aromatic polyamides by direct polycondensation Macromolecules, 26 (1993), pp. 4984-4985

35. Y. Alsaid, S. Wu, D. Wu, Y. Du, L. Shi, R. Khodambashi et al. Tunable Sponge-Like Hierarchically Porous Hydrogels with Simultaneously Enhanced Diffusivity and Mechanical Properties Adv. Mater., 33 (2021), p. 2008235

36. G. Nazir, A. Rehman, S. J. Park Sustainable N-doped hierarchical porous carbons as efficient $\mathbf{C O}_{2}$ adsorbents and high-performance supercapacitor electrodes J. CO2 Util., 42 (2020), p. 101326

37. B.Y. Guan, A. Kushima, L. Yu, S. Li, J. Li, X.W. Lou et al., Coordination polymers derived general synthesis of multishelled mixed metal-oxide particles for hybrid supercapacitors. Adv. Mater. 29, 1605902 (2017)

38. M. Zare, N. Parvin, M.P. Prabhakaran, J.A. Mohandesi, S. Ramakrishna Highly porous 3D spongelike shape memory polymer for tissue engineering application with remote actuation potential Compos. Sci. Technol., 184 (2019), p. 107874 
39. A. Rehman, G. Nazir, K.Y. Rhee, S.J. Park A rational design of cellulose-based heteroatom-doped porous carbons: Promising contenders for $\mathrm{CO}_{2}$ adsorption and separation Chem. Eng. J., 420 (2021), p. 130421

40. A. Gul, Z. Akhter, A. Bhatti, M. Siddiq, A. Khan, H.M. Siddiqe et al. Synthesis, physicochemical studies and potential applications of high-molecular-weight ferrocene-based poly (azomethine) ester and its soluble terpolymers J. Organomet. Chem., 719 (2012), pp. 41-53

\section{Scheme}

Scheme $1 \& 2$ are available in the Supplementary Files section.

\section{Figures}

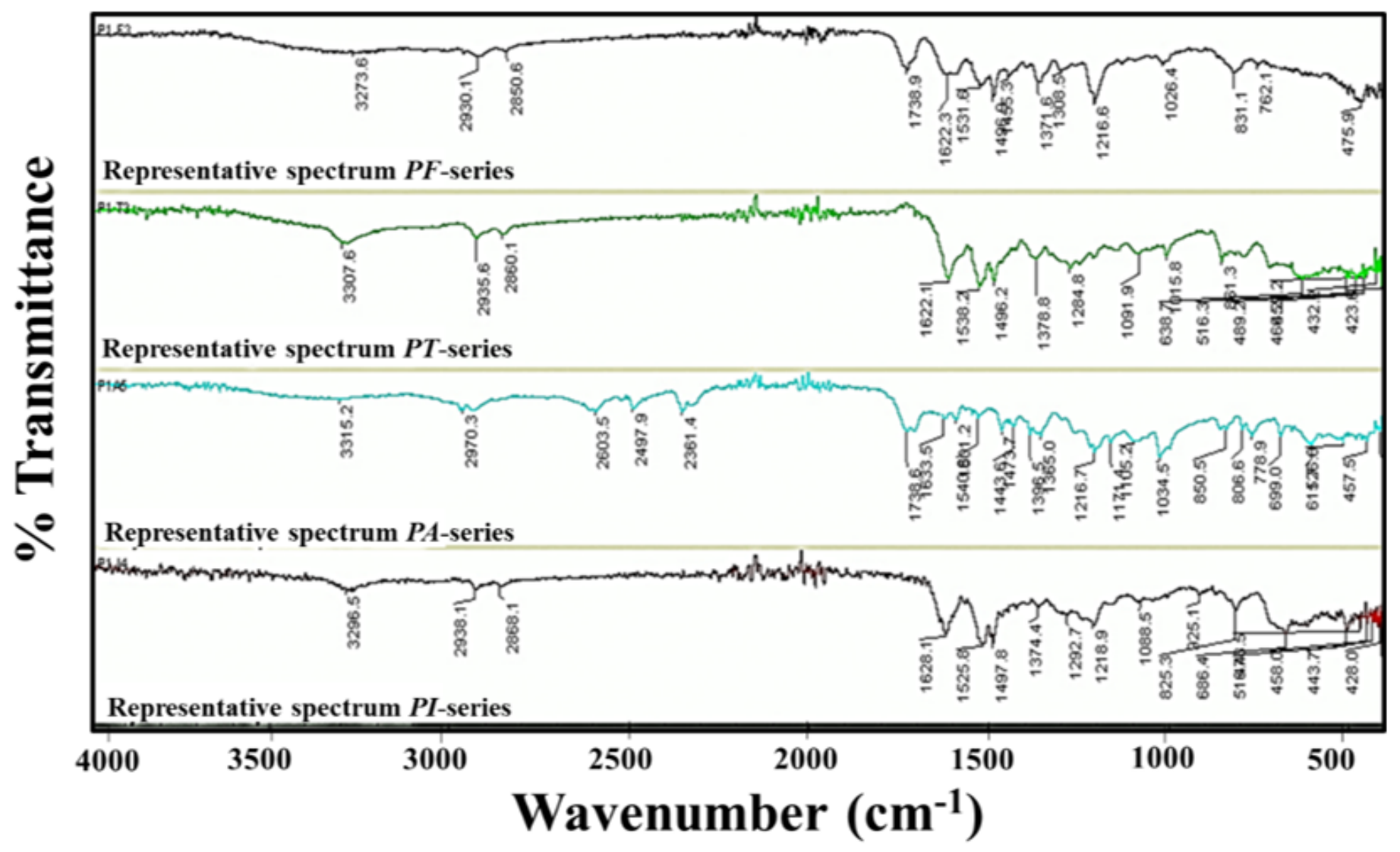

Figure 1

Representative FT-IR spectra of Terpolyamides series PF, PT, PA, and PI, respectively. 


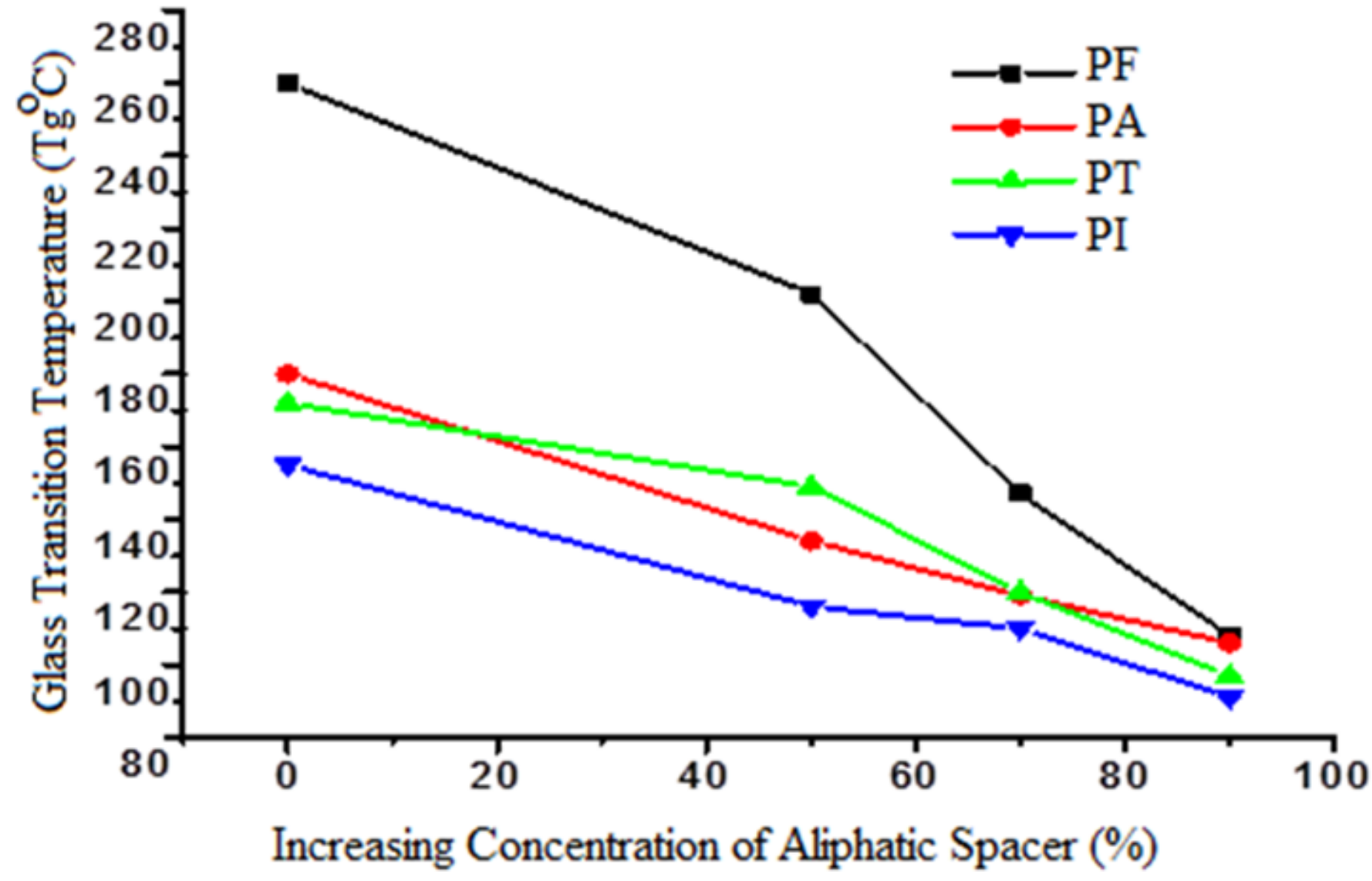

Figure 2

Variation in $T g$ with increasing concentration of aliphatic spacer. 


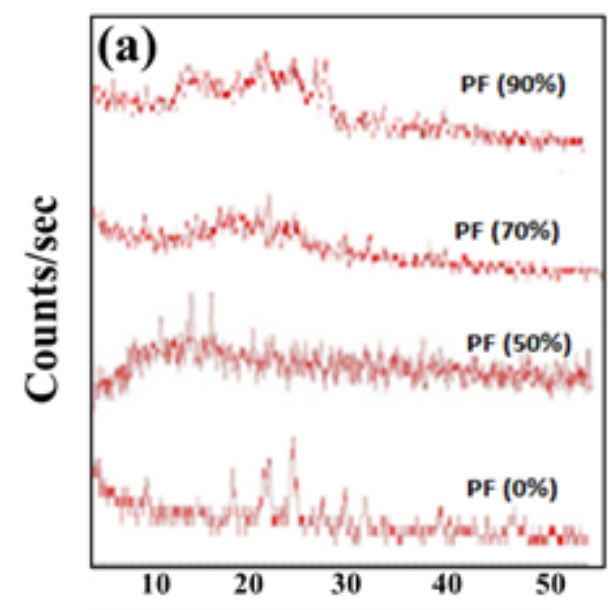

Position (20)

Organometallic polyamides

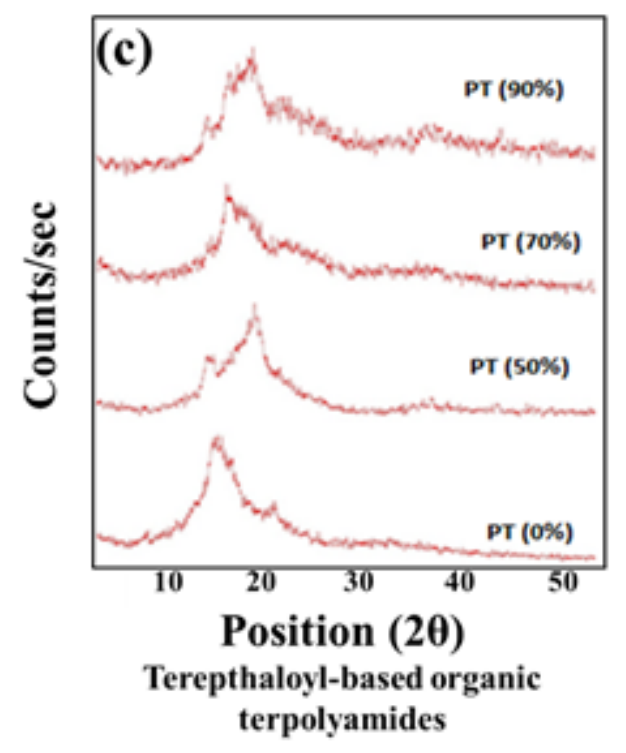

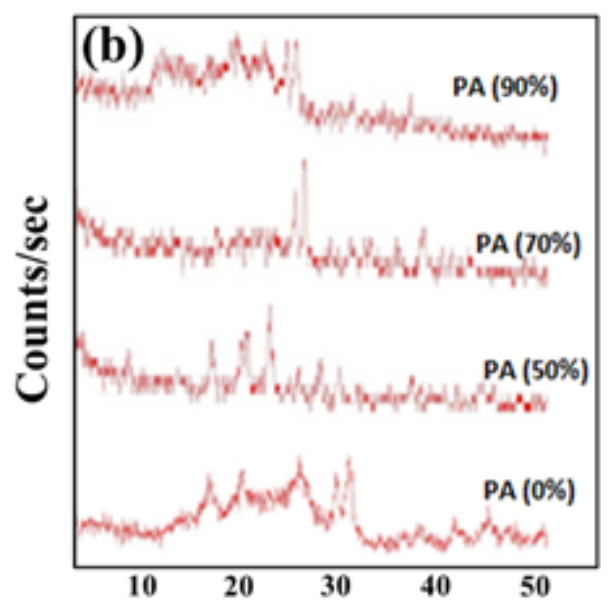

Position (20)

Azo-based organic terpolyamides

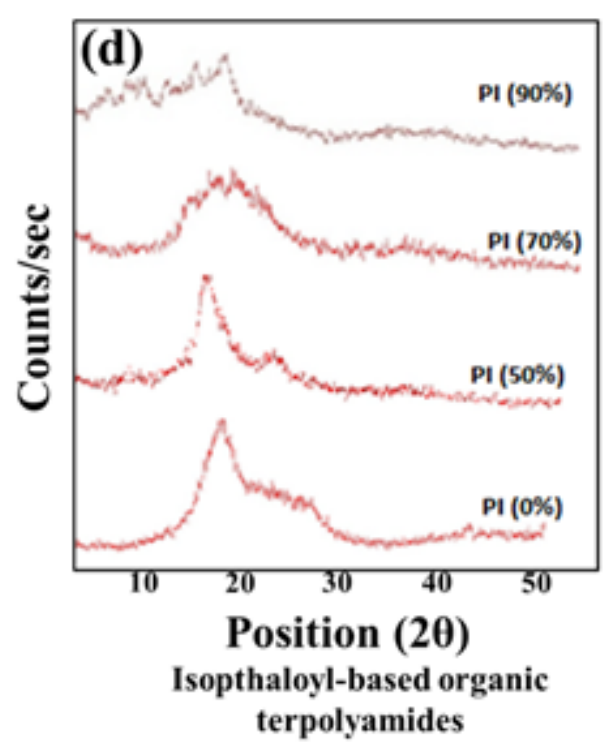

Figure 3

WAXRD patterns for (a) Organometallic polyamides, (b) Azo-based organic terpolyamides, (c) Terepthaloyl-based organic terpolyamides and (b) Isopthaloyl-based organic terpolyamides polymers. 

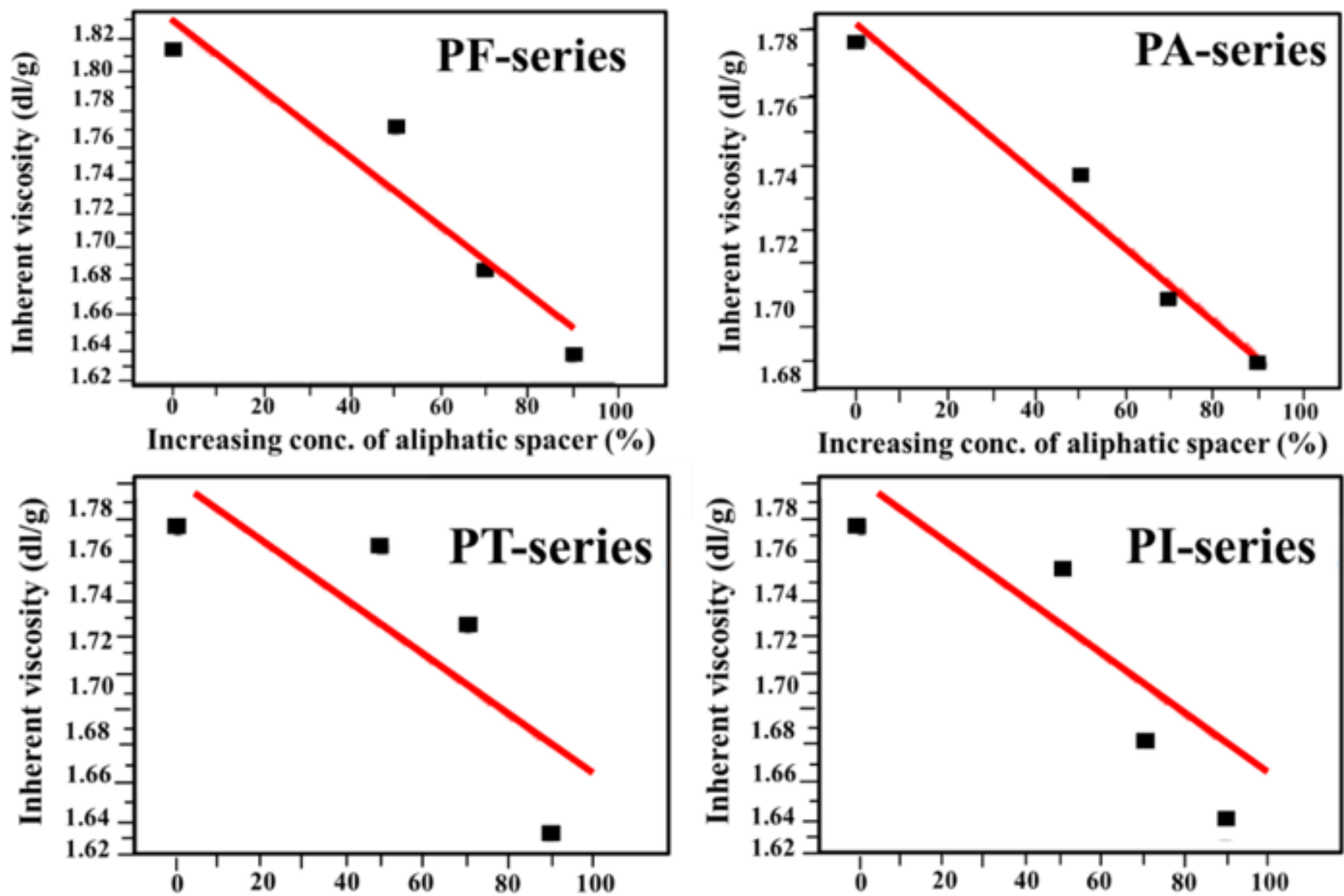

Increasing conc. of aliphatic spacer (\%)

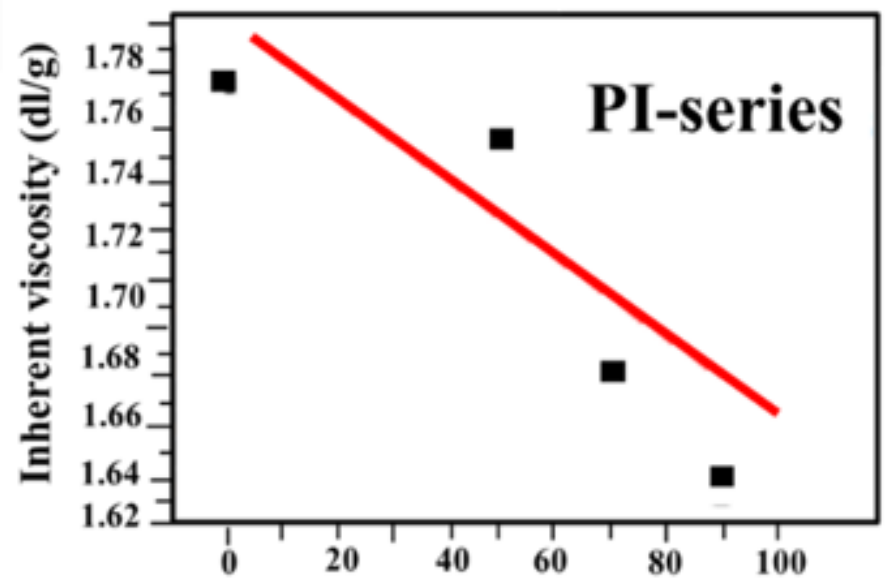

Increasing conc. of aliphatic spacer (\%)

Figure 4

Viscosity Composition Plots of Organometallic and organic terpolyamides. 

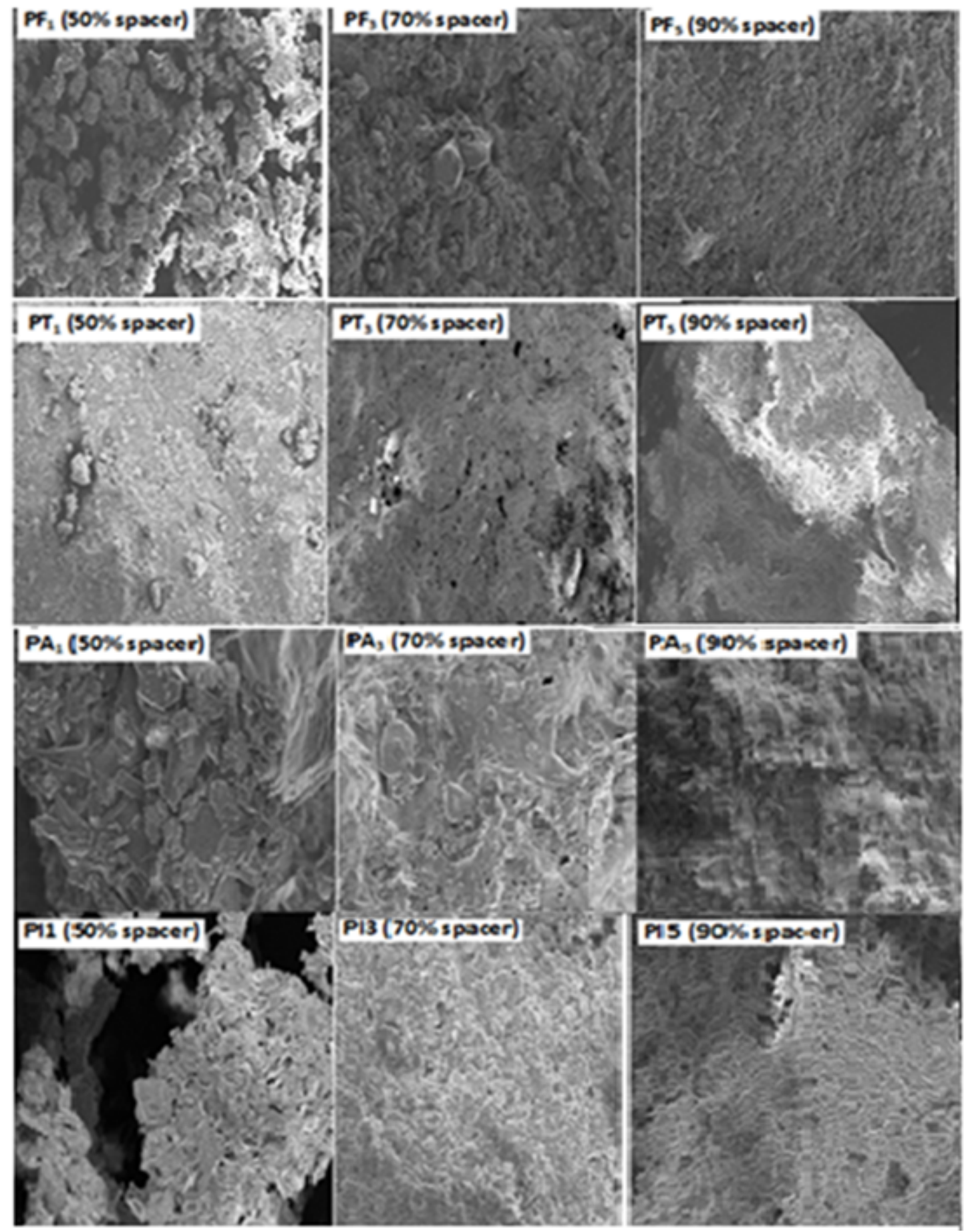

Figure 5

Scanning electron micrographs of terpolyamides.

\section{Supplementary Files}

This is a list of supplementary files associated with this preprint. Click to download. 
- Scehem1.png

- Scheme2.png

Page 20/20 